\title{
Why Do Students Have Difficulties Completing Homework? The Need for Homework Management
}

\author{
Jianzhong $\mathrm{Xu}^{1}$ \\ ${ }^{1}$ Department of Leadership and Foundations, Mississippi State University, USA \\ Correspondence: Jianzhong $\mathrm{Xu}$, Department of Leadership and Foundations, Box 6037, Mississippi State \\ University, Mississippi State, MS 39762, USA. Tel: 1-662-325-2186. E-mail: jx18@colled.msstate.edu
}

Received: January 14, 2013 Accepted: February 19, 2013 Available online: February 27, 2013

doi:10.11114/jets.v1i1.78

URL: http://dx.doi.org/10.11114/jets.v1i1.78

\begin{abstract}
Homework is a common and widespread educational activity. Yet, as homework often takes place amidst the pull of more attractive and competing after-school activities, doing homework presents multiple challenges for many students, even for those students who find their assignments meaningful and interesting. In this article, I first examine five major homework challenges, including arranging a conducive homework environment, budgeting time and pacing themselves to meet homework deadlines, handling homework distractions, keeping themselves motivated during homework sessions, and coping with negative affect or mood swings encountered while doing homework. I then discuss a range of strategies that students may use to deal with these challenges as well as implications for teachers and families seeking to help students manage their homework more responsibly.
\end{abstract}

Keywords: homework, homework management, self-regulation

\section{Introduction}

Although public attitudes toward homework have periodically shifted back and forth over the one hundred years (Gill \& Schlossman, 2004), homework continues to be a common educational activity; and for most school-age children it is an important part of their daily routine (Cooper, Robinson, \& Patall, 2006; Corno, 2000). As homework takes place amidst the pull of more attractive and competing after-school activities, doing homework presents multiple challenges for many students, even for those students who find their assignments meaningful and interesting. One challenge is how to arrange a conducive homework environment (e.g., with a quiet and adequate workspace; Hong \& Milgram, 1999; Pool, van der Voort, Beentjes, \& Koolstra, 2000; Xu \& Corno, 2003). A related challenge is how to manage time to meet homework deadlines, avoiding procrastination of homework assignments until the last minute (Corno, 1996; Xu, 2010b; Xu \& Corno, 1998).

Another challenge is how to deal with various conventional distractions that often arise while doing homework (e.g., phone calls and TV; Xu \& Corno, 1998) as well as high-tech distractions (e.g., the allure of Web surfing, online chatting, text messaging, and blogging; Foehr, 2006; Wallis, 2006; Xu, 2010a). Other challenges are related to children's lower motivational and emotional states while doing homework (Corno, 2001; Kouzma \& Kennedy, 2002; Verma, Sharma, \& Larson, 2002). Indeed, for many children, doing homework becomes an “'emotionally charged”' event (Corno, 1996, 2000), from generally negative emotional states (Verma et al., 2002) to situations where they feel so frustrated that they are unable to do any homework for the night (Begley, 1998; Corno \& Xu, 2004; Xu \& Corno, 1998).

It is not surprising to note that homework often becomes "a source of complaint and friction between home and school more often than other teaching activities” (Cooper, 2001, p. ix). Students often view doing homework as one of their least favorite after-school activities (Warton, 2001; Xu \& Yuan, 2003). Indeed, trying to get students to complete homework has become one of the most frequent and frustrating behavioral problems for educators (Killoran, 2003).

It is surprising to note, however, that much of the discussion on the homework behavioral problem has centered on the role of teachers and parents in the homework process rather than the role of students themselves (Xu, 2005). Until recently, little attention has been paid to how to develop students' self-regulatory capabilities (i.e. homework management strategies) and to help them assume more responsibility to navigate the demands of doing homework. 
Consequently, it would important to focus on the following question: How can teachers and families promote students' use of homework management strategies in the homework process? This question is particularly important, as the use of homework management strategies is positively associated with homework completion (Xu, 2008a, 2008b; Xu \& Corno, 1998) and academic achievement (Ramdass \& Zimmerman, 2011; Xu, 2009).

In this article, I first discuss one theoretical framework relevant to homework management. I then turn to the method I use to find related literature to be included for this review. Following that, I discuss how educators can help students to take initiative and use homework management strategies to address these five homework challenges (i.e., arranging the environment, managing time, handling distraction, monitoring motivation, and controlling emotion).

\section{Theoretical Framework}

One theoretical framework that taps into homework management is self-regulated learning (Pintrich, 2004; Zimmerman, 2008), particularly from the perspective of volitional control (Boekaerts \& Corno, 2005; Corno, 2001; Kuhl, 2000; Winne, 2004). Volitional control is mainly concerned with issues of implementation (i.e., an implementation mindset) that occur after a goal is set, to protect the intention to pursue that goal in the face of an array of alluring distractions, enticing temptations, or competing personal strivings (Corno, 2004). Particularly, it is characterized by the self-regulation activities of purposive and persistent striving, including, for example, planning goals, setting priorities, budgeting time, coping with distractions, controlling motivation, and monitoring emotion (Boekaerts \& Corno, 2005; Corno, 2004).

Volitional control is especially important to the task of homework management because goals of homework tasks are typically set by teachers; the main charge for students is to navigate the demands of doing homework (i.e., engaging purposively in maneuvers that effectively protect homework intention). They are asked to maintain the needed focus and effort to complete homework assignments, with less structure, supervision, social pressures, and time constraints than exist in the classroom (Cooper et al., 2006; Trautwein \& Koller, 2003; Wolters, 2003). They are required to independently manage homework, including organizing the study environment, allocating their time, preventing or minimizing homework distractions, maintaining or enhancing the strength of homework intention, and coping with negative emotions surrounding homework tasks (Corno, 2004; Xu, 2010a).

Informed by Corno's model on volitional control, Xu and Corno (2003) developed five features of homework management, including arranging environment, managing time, focusing attention, monitoring motivation, and controlling emotion. These features of homework management constitute a set of skills that have often been assumed, yet rarely examined empirically (e.g., Cooper \& Valentine, 2001; Hoover-Dempsey, Bassler, \& Burow, 1995). Taken together, these efforts to manage homework reflect an underlying self-regulation construct that has been independent of academic achievement and ability measures in other research (see Stanford Aptitude Seminar, 2002).

Recently, based on the previous version of the five features of homework management strategies (Xu \& Corno, 2003), Xu (2008a, 2008b) further developed and tested the validity of scores on Homework Management Scale (HMS) within the framework of structural equation modeling. Factor-analytic results revealed that the scale comprised five separate yet related factors: arranging the environment, managing time, handling distraction, monitoring motivation, and controlling emotion. Results further revealed that the HMS differentiated among middle and high school students who were more or less likely to complete homework assignments.

\section{Method}

In January 2013, the following steps were taken on articles to be included in this review. First, the EBSCO database (Academic Search Premier) was used to find full text articles on homework management (i.e., using the search term of "homework management"). Following that, the ERIC database was used to locate articles on homework management using the same procedure. Both searches amounted to 16 articles. In addition, the Scopus database was used to search for articles on "homework management," which resulted in 13 articles. Taken together, these three searches (i.e., the EBSCO, the ERIC, and the Scopus) produced total 24 articles.

For an article to be included in this review, it had to focus on homework management at the elementary or secondary school level. In addition, it had to focus on regular students with conventional homework. It was felt that the issue of homework management would be very different for those students with learning disability or through the use of computer-based management system. As a result, 7 out of 24 articles were excluded from this review (4 articles focusing on web-based or computer-based management system, and 3 articles focusing on learning disability). 


\section{Arranging the Environment}

Arranging the environment or environmental structuring refers to individuals' efforts to structure, control, or regulate certain features of their environment to make it more conducive for studying and task completion (Wolters, 2003; Xu \& Corno, 1998; Zimmerman, 2008). It involves creating or arranging a quiet area for studying (e.g., turning off television and moving away from noise) and asking others (e.g., family members) to keep unrelated conversations to a minimum during the study period. It also involves organizing homework materials, clearing off the table, creating adequate workspace, and removing potentially distracting materials (e.g., toys or cell phone).

Several empirical studies indicate that a number of factors influence homework environment management, including family homework help, teacher feedback, homework interest, and purposes for doing homework (Deslandes, Rousseau, \& Nadeau, 2008; Trautwein, Ludtke, Schnyder, \& Niggli, 2006; Xu, 2005, 2012; Xu \& Corno, 1998). Consequently, several implications can be drawn from this line of research. First, the importance of family help and teacher feedback suggests that families and teachers can exert their influence on homework environment management, well into the secondary school years. Thus, adolescents can still benefit from adult monitoring (e.g. how to choose, arrange, adapt, and create a productive homework environment), particularly as the data from one recent study $(\mathrm{Xu}, 2012)$ revealed that moving from grade 8 to grade 11 by and in itself did not mean that they were ready to take more initiative in managing their homework environment.

In addition, as homework interest and learning-oriented purposes (i.e., doing homework for reinforcing school learning and developing a sense of responsibility) are positively related to homework environment management, teachers and families need to make a more coordinated effort to help students explore ways to make homework more purposeful and engaging during after-school hours. This, in turn, will encourage students to take more initiative to manage homework environment in the process. For example, teachers can make homework assignments more purposeful and interesting through homework design and homework feedback. Likewise, parents can make homework environment more manageable for children by providing a quiet study area and making themselves more readily available (Xu, 2012). Finally, it would be beneficial to pay close attention to students' voices about what schools or families may do to help them better manage homework environment (Nathan, 1996), so that teachers and parents can better support students' efforts at homework environment management. As a result, students are more likely to be empowered to take more responsibility for arranging the study environment in the process.

\section{Managing Time}

Managing time refers to individuals' efforts to budget time to meet homework deadlines (e.g., creating study schedules and allocating time for different activities), from time planning to monitoring and regulating time use (Xu, 2010b; Xu \& Corno, 1998). It involves setting priorities and planning ahead, scheduling regular time to do homework in the midst of other after-school activities, and pacing oneself to complete several assignments with different due dates. It also involves keeping track of what remains to be done (e.g., listing homework assignments on one sheet and then checking off the assignments as they are finished), and reminding themselves of the available time left.

One recent study finds that the influence of family homework help and teacher feedback on homework time management is mediated by homework purposes as perceived by secondary school students (Xu, 2010b). This finding suggests that teachers and parents can still play an important on homework time management at the secondary school level. This is an important message for secondary school teachers in particular, as they tend to place less value on managing homework time than do elementary school teachers (Muhlenbruck, Cooper, Nye, \& Lindsey, 2000). In addition, there is a critical need to pay close attention to purposes of homework as perceived by students. Specifically, there is a need to help students inject personal meaning into their homework, viewing it as an important vehicle for reinforcing school learning and for developing a sense of responsibility.

It is interesting to note that students often have their own preference about how to budget time. For example, one girl thought that the best time to do her homework was after dinner because "I don't have to eat while I'm doing something [related to homework]. I can just keep something moving, and I don't have to stop to do anything else." However, one boy thought it was right after he got home, "so you can get it over with, and then you have more time for playing a game," without having to "stop right in the middle of it." Thus, rather than imposing their own preference on children, it would be important for teachers and parents to encourage children to develop a routine and rhythm that works for them. It would be equally important to listen to them discuss their strategies or worked examples of how they allocate and manage homework time, as well as hear their suggestions about what schools or families may do to help them to better manage homework time. 


\section{Handling Distraction}

Handling distraction refers to students' efforts to discriminate task-relevant information from that of unrelated activities and to keep their attention focused on the demands of the specific task at hand (Xu \& Corno, 1998). It involves not paying attention to unrelated activities around them (e.g., conversations among family members or text messages from friends) and not to engage other unrelated activities that would distract them from homework (e.g., Web surfing or online chatting).

One recent study (Xu, 2010a) finds that homework distraction was related to gender, grade level, the context of doing homework at home, and student attitudes toward homework. Specifically, girls (compared with boys) and 11th graders (compared with 8th graders) are more likely to be distracted while doing homework. In addition, students' desires to engage in other after-school activities (e.g., television, sports, and other extracurricular activities) are positively related to homework distraction. On the other hand, those students with higher scores in adult-oriented and learning-oriented reasons are more likely to take initiatives to overcome homework distraction.

These findings suggest that teachers and parents need to exert their influence strategically by structuring and prioritizing other after-school activities (e.g., sports and other extracurricular activities), with more attention to girls and older teens. They also need to help students to see the value of doing homework - view it as closing critical gaps in academic experiences (learning-oriented reasons) or fulfilling expectations of significant others (adult-oriented reasons). As a result, they are more likely to take initiative to protect their attention against potential homework distraction. Meanwhile, students need to take more responsibility about how to prioritize and structure other after-school activities on a weekly basis so that they are less likely to be sidetracked by thoughts of competing activities while doing daily homework.

It is important to note that, in some cases, what is considered as "distracting" by one student may not be viewed as distracting by another student. Certain distractions may have beneficial qualities (e.g., as a motivational or emotional aid). Similarly, some "distractions" (e.g., background music) may have the effect of increasing the length of time that the child works on an assignment (Xu \& Corno, 2003). As a result, it would be important for teachers and parents to encourage students to play an important role to learn to identify and deal with homework distraction in the homework process.

\section{Monitoring Motivation}

Monitoring motivation refers to students' efforts to purposefully monitor their motivation, to initiate, maintain, or supplement their willingness to start, to follow through, and to complete a task that might be boring or difficult (Pintrich, 2004; Wolters, 2003). It involves self-consequating (e.g., praising themselves for good work or good efforts; Wolters, 2003; Xu \& Corno, 1998), interest enhancement (e.g., finding ways to make homework assignments more interesting for themselves; Wolters, 2003), and efficacy self-talk (e.g., reassuring themselves that they are able to do their homework appropriately; McCann \& Garcia, 1999).

Several studies find that homework motivation management is positively related to a number of variables, including family homework help, homework interest, and homework purposes as perceived by students (Deslande et al., 2008; Xu, 2005; Xu \& Corno, 1998). These findings suggest that it would be beneficial for teachers to make homework more interesting, relevant, and engaging for students so that they are more like to take initiative to monitor their homework motivation in the process. Similarly, it would be beneficial for teachers and parents to model motivational regulation strategies, including positive self-talk (e.g., challenge themselves to work hard to complete a difficult task), self-consequating (e.g., make a deal with themselves that if they get homework done they can do something they like afterwards), and interest enhancement (e.g., find ways to make a task more interesting). As student attitude (e.g., learning-oriented reasons) can play an important role in homework motivation management, teachers and parents need to find ways to promote more positive homework attitudes. It would also be beneficial to encourage students to discuss and share their homework management strategies with peers (Nathan, 1996), which may help to promote "social aspects of motivation" (Wentzel \& Wigfield, 2007, p. 262) and social aspects of motivation management for timely homework completion.

Some students tended to enhance their motivation to complete homework by looking forward to playtime (e.g., to get homework over with so that they have more time to play) and seeking adult approval (e.g., "My dad says I have to get good grades, so I do homework even if I don’t feel like it.”). Thus, teachers and parents need to be mindful about what strategies students choose to monitor their motivation and gradually encourage them to use intrinsic strategies (e.g., making homework more interesting and reassuring themselves). 


\section{Controlling Emotion}

Controlling emotion refers to students' effort to monitor and modify the occurrence, intensity, and expression of emotions (Eisenberg, Champion, \& Ma, 2004) and to use reassurance to control negative affect or redirect an emotional response (Corno, 1986; Xu, 2006). As homework typically elicits unpleasant emotional responses (Verma et al., 2002), controlling homework emotion often involves down-regulating unpleasant emotions (e.g., “Tell myself not to be bothered with previous mistakes") and up-regulating positive emotions (e.g., "Cheer myself up by telling myself that I can do it”).

One recent study $(\mathrm{Xu}, 2011)$ finds that the positive effects of teacher feedback and family homework help are partly mediated by the role of students in the homework process (e.g., student attitude toward homework). In addition, girls (compared with boys) are more likely to monitor their emotion while doing homework. These findings suggest that teachers and parents can exert their influence indirectly on homework emotion management at the secondary school level. Specifically, teachers and parents need to pay more attention to boys doing homework during the secondary school years, as families of secondary school students tend to be more involved in girls' homework than that of boys (Cooper, Lindsay, \& Nye, 2000; Xu, 2005).

Furthermore, it would be critical for schools to pay close attention to students' own voices as to how their emotional sequences unfold while doing homework and how these sequences are influenced by other factors in students' lives. Specifically, it would be beneficial to listen to students discuss their coping strategies or worked examples in managing homework emotion. Indeed, as shown in one previous study (Xu \& Corno, 1998) that some students are capable of managing their emotion from time to time. During homework sessions, for example, students were using positive self-talk (e.g., "That should be easy.”). Some students were able to calm themselves after feeling frustration or disappointed with their work. When one boy became frustrated with his homework, he said he sat in his chair quietly for a while, tried to "think of something else to do or just go to another homework assignment." Instead of thinking, "This is not going to work because this is too hard," another girl said she tried to look on "the bright side." She cheered herself up by telling herself, "I know I can do it." This overt statement of self-efficacy helped her, she said, to see that it could become easier for her.

Finally, it would be beneficial to listen to students about specific suggestions regarding what schools or families may do to help them to cope with unpleasant homework emotion. Armed with such information, teachers and parents can provide more appropriate support for their efforts at homework emotion management. This, in turn, will encourage students to play a more constructive role in managing homework emotion (e.g., developing and experimenting with their implicit theories about beneficial conditions for dealing with homework emotion).

\section{Conclusion}

In this article, I have discussed five major homework challenges that students typically encounter in the homework process (i.e., arranging the environment, managing time, handling distraction, monitoring motivation, and controlling emotion). Then, I have focused on how educators can promote students' use of homework management strategies in the homework process, in line with (a) a perspective from self-regulated learning in general (with volitional control in particular) and (b) relevant empirical studies on homework management strategies.

It is important to note that students often face multiple homework challenges simultaneously (e.g., boring assignments and unpleasant homework-related emotions) and that these challenges are frequently related. For example, a student is more likely to be distracted when she considers her homework assignments as boring, which, in turn, may elicit a more negative emotional response from her. Consequently, it would be important for teachers and families to work together to coordinate homework management strategies, as suggested by data from a qualitative study (Xu \& Corno, 1998) that, for example, "arranging a favorable homework environment and allowing the child to choose the order of completion seemed to enhance the children's attentiveness and sustain motivation better than either strategy alone" (p. 430). The importance of such a coordination is further substantiated by the empirical findings that these features of homework management strategies are separate yet related features (Xu, 2008a, 2008b).

This article could prove valuable as homework completion becomes one of the most frequent and frustrating behavioral problems for teachers, students, and their families. An article such as this is particularly important and timely, as it (a) points to the need to reframe the larger conversation about homework challenges and homework completion and (b) provides practical strategies, along with illustrative examples, about how to make homework more manageable for teachers, students, and their families. 
It is time to put emphasis on encouraging and empowering students to play a more prominent role in homework management. Teachers and families have a vested interest in seeing students learn to self-regulate their own studying (e.g., managing time, handling distraction, and coping with negative emotion). Aside from addressing the homework behavioral problem, learning how to manage homework provides recurring opportunities for students to develop good study habits and to become autonomous, lifelong learners outside formal educational settings.

\section{References}

Begley, S. (1998, March 30). Homework doesn’t help. Newsweek, 131(13), 50-51.

Boekaerts, M., \& Corno, L. (2005). Self-regulation in the classroom: A perspective on assessment and intervention. Applied Psychology: An International Review, 54, 199-231. http://dx.doi.org/10.1111/j.1464-0597.2005.00205.x

Cooper, H. (2001). The battle over homework: Common ground for administrators, teachers, and parents (2nd ed.). Thousand Oaks, CA: Corwin.

Cooper, H., Lindsay, J. J., \& Nye, B. (2000). Homework in the home: How student, family and parenting-style differences relate to the homework process. Contemporary Educational Psychology, 25, 464-487. http://dx.doi.org/10.1006/ceps.1999.1036

Cooper, H., Robinson, J. C., \& Patall, E. A. (2006). Does homework improve academic achievement? A synthesis of research, 1987-2003. Review of Educational Research, 76, 1-62. http://dx.doi.org/10.3102/00346543076001001

Cooper, H., \& Valentine, J. C. (2001). Using research to answer practical questions about homework. Educational Psychologist, 36, 143-153. http://dx.doi.org/10.1207/S15326985EP3603_1

Corno, L. (1986). The metacognitive control aspects of self-regulated learning. Contemporary Educational Psychology, 11, 333-346. http://dx.doi.org/10.1016/0361-476X(86)90029-9

Corno, L. (1996). Homework is a complicated thing. Educational Researcher, 25(8), 27-30.

Corno, L. (2000). Looking at homework differently. Elementary School Journal, 100, 529-548. http://dx.doi.org/10.1086/499654

Corno, L. (2001). Self-regulated learning: A volitional analysis. In B. Zimmerman \& D. Schunk (Eds.), Self-regulated learning and academic achievement: Theory, research, and practice (Vol. 2, pp. 111-142). Mahwah, NJ: Lawrence Erlbaum.

Corno, L. (2004). Introduction to the special issue work habits and work styles: Volition in education. Teachers College Record, 106, 1669-1694. http://dx.doi.org/10.1111/j.1467-9620.2004.00400.x

Corno, L., \& Xu, J. (2004). Doing homework as the job of childhood. Theory into Practice, 43, 227-233. http://dx.doi.org/10.1207/s15430421tip4303_9

Deslandes, R., Rousseau, M., \& Nadeau, T. (2008, March). Evolution and relationship of students' homework management strategies and their parents' help in homework during the transition to high school. Paper presented at the Annual Meeting of American Educational Research Association, New York, NY.

Eisenberg, N., Champion, C., \& Ma, Y. (2004). Emotion-related regulation: An emerging construct. Merrill-Palmer Quarterly, 50, 236-259. http://dx.doi.org/10.1353/mpq.2004.0016

Foehr, U. G. (2006). Media multitasking among American youth: Prevalence, predictors, and pairings. Menlo Park, CA: Kaiser Family Foundation.

Gill, B. P., \& Schlossman, S. L. (2004). Villain or savior? The American discourse on homework, 1850-2003. Theory into Practice, 43, 174-181. http://dx.doi.org/10.1207/s15430421tip4303_2

Hong, E., \& Milgram, R. M. (1999). Preferred and actual homework style: A cross-cultural examination. Educational Research, 41, 251-265. http://dx.doi.org/10.1080/0013188990410302

Hoover-Dempsey, K. V., Bassler, O. C., \& Burow, R. (1995). Parents' reported involvement in students' homework: Strategies and practices. Elementary School Journal, 95, 435-450. http://dx.doi.org/10.1086/461854

Killoran, I. (2003). Why is your homework not done? How theories of development affect your approach in the classroom. Journal of Instructional Psychology, 30, 309-315. 
Kouzma, N. M., \& Kennedy, G. A. (2002). Homework, stress, and mood disturbance in senior high school students. Psychological Reports, 91, 193-198.

Kuhl, J. (2000). The volitional basis of personality systems interaction theory: Applications in learning and treatment contexts. International Journal of Educational Research, 33, 665-704. http://dx.doi.org/10.1016/S0883-0355(00)00045-8

McCann, E., \& Garcia, T. (1999). Maintaining motivation and regulating emotion: Measuring individual differences in academic volitional strategies. Learning and Individual Differences, 3, 250-279.

Muhlenbruck, L., Cooper, H., Nye, B., \& Lindsey, J. J. (2000). Homework and achievement: Explaining the different strengths of relation at the elementary and secondary school levels. Social Psychology of Education, 3, 295-317. http://dx.doi.org/10.1023/A:1009680513901

Nathan, A. (1996). Surviving homework: Tips from teens. Brookfield, CT: Millbrook Press.

Pintrich, P. R. (2004). A conceptual framework for assessing motivation and self-regulated learning in college students. Educational Psychology Review, 16, 385-407. http://dx.doi.org/10.1007/s10648-004-0006-x

Pool, M. M., van der Voort, T. H. A., Beentjes, J. W. J., \& Koolstra, C. M. (2000). Background television as an inhibitor of performance on easy and difficult homework assignments. Communication Research, 27, 293-326. http://dx.doi.org/10.1177/009365000027003002

Ramdass, D., \& Simmerman, B. J. (2011). Developing self-regulation skills: The important role of homework. Journal of Advanced Academics, 22, 194-218. http://dx.doi.org/10.1177/1932202X1102200202

Stanford Aptitude Seminar. (2002). Remaking the concept of aptitude: Extending the legacy o Richard E. Snow. Mahwah, NJ: Erlbaum.

Trautwein, U., \& Koller, O. (2003). The relationship between homework and achievement - still much of a mystery. Educational Psychology Review, 15, 115-145. http://dx.doi.org/10.1023/A:1023460414243

Trautwein, U., Ludtke, O., Schnyder, I., \& Niggli, A. (2006). Predicting homework effort: Support for a domain-specific, multilevel homework model. Journal of Educational Psychology, 98, 438-456. http://dx.doi.org/10.1037/0022-0663.98.2.438

Verma, S., Sharma, D., \& Larson, R. W. (2002). School stress in India: Effects on time and daily emotions. International Journal of Behavior Development, 26, 500-508. http://dx.doi.org/10.1080/01650250143000454

Wallis, C. (2006, March 27). The multitasking generation: They're e-mailing, IMing and downloading while writing the history essay. What is all that digital juggling doing to kids' brains and their family life? Time, 167, 48-55.

Warton, P. M. (2001). The forgotten voices in homework: Views of students. Educational Psychologist, 36, 155-165. http://dx.doi.org/10.1207/S15326985EP3603_2

Wentzel, K. R., \& Wigfield A. (2007). Motivational interventions that work: Themes and remaining issues. Educational Psychologist, 42, 261-271. http://dx.doi.org/10.1080/00461520701621103

Winne, P. H. (2004). Putting volition to work in education. Teachers College Record, 106, 1879-1887. http://dx.doi.org/10.1111/j.1467-9620.2004.00409.x

Wolters, C. A. (2003). Regulation of motivation: Evaluating an underemphasized aspect of self-regulated learning. Educational Psychologist, 38, 189-205. http://dx.doi.org/10.1207/S15326985EP3804_1

Xu, J. (2005). Purposes for doing homework reported by middle and high school students. Journal of Educational Research, 99, 46-55. http://dx.doi.org/10.3200/JOER.99.1.46-55

Xu, J. (2006). Gender and homework management reported by high school students. Educational Psychology, 26, 73-91. http://dx.doi.org/10.1080/01443410500341023

$\mathrm{Xu}, \mathrm{J}$. (2008a). Validation of scores on the homework management scale for high school students. Educational and Psychological Measurement, 68, 304-324.

$\mathrm{Xu}, \mathrm{J}$. (2008b). Validation of scores on the homework management scale for middle school students. Elementary School Journal, 109, 82-95. http://dx.doi.org/10.1086/592368

$\mathrm{Xu}$, J. (2009). School location, student achievement, and homework management reported by middle school students. School Community Journal, 19(2), 27-43. 
Xu, J. (2010a). Predicting homework distraction at the secondary school level: A multilevel analysis. Teachers College Record, 112, 1937-1970.

Xu, J. (2010b). Predicting homework time management at the secondary school level: A multilevel analysis. Learning and Individual Differences, 20, 34-39. http://dx.doi.org/10.1016/j.lindif.2009.11.001

$\mathrm{Xu}, \mathrm{J}$. (2011). Homework emotion management at the secondary school level: Antecedents and homework completion. Teachers College Record, 113, 529-560.

Xu, J. (2012). Predicting students' homework environment management at the secondary school level. Educational Psychology, 32, 183-200. http://dx.doi.org/10.1080/01443410.2011.635639

Xu, J., \& Corno, L. (1998). Case studies of families doing third-grade homework. Teachers College Record, 100, 402-436.

Xu, J., \& Corno, L. (2003). Family help and homework management reported by middle school students. Elementary School Journal, 103, 503-518. http://dx.doi.org/10.1086/499737

Xu, J., \& Yuan, R. (2003). Doing homework: Listening to students', parents', and teachers' voices in one urban middle school community. School Community Journal, 13(2), 25-44

Zimmerman, B. J. (2008). Investigating self-regulation and motivation: Historical background, methodological developments, and future prospects. American Educational Research Journal, 45, 166-183. http://dx.doi.org/10.3102/0002831207312909

\section{(cc) $\mathrm{BY}$}

This work is licensed under a Creative Commons Attribution 3.0 License. 